\title{
High Cycle Fatigue Property of Extruded Non-Combustible Mg Alloy AMCa602
}

\author{
Kiyotaka Masaki ${ }^{1}$, Yasuo Ochi ${ }^{2}$, Toshifumi Kakiuchi ${ }^{2}$, Keiichi Kurata ${ }^{2}{ }^{* 1}$, Toru Hirasawa ${ }^{2}{ }^{2}$, \\ Takashi Matsumura $^{2}$, Yorinobu Takigawa ${ }^{3}$ and Kenji Higashi ${ }^{3}$ \\ ${ }^{1}$ Department of Mechanical Systems Engineering, Okinawa National College of Technology, Nago 905-2192, Japan \\ ${ }^{2}$ Department of Mechanical Engineering \& Intelligent Systems, University of Electro-Communications, \\ Tokyo (UEC, Tokyo), Tokyo 182-8585, Japan \\ ${ }^{3}$ Department of Materials Science, Graduate School of Engineering, Osaka Prefecture University, Sakai 599-8531, Japan
}

Rotating bending tests were performed at room temperature on the non-combustible magnesium alloy AMCa602, which was produced by adding $2 \%$ calcium $(\mathrm{Ca})$ to the AM60 magnesium alloy. The fatigue strength at $10^{7}$ cycles was approximately $100 \mathrm{MPa}$. The fatigue property was strongly dependent on the inclusion size. In order to identify the type of the inclusion at the crack initiation site, elemental analyses were conducted by an electron probe microanalyzer (EPMA). The inclusion at the crack initiation site was AlN, which may have originated from impurities mixed in during casting. The relation between $\mathrm{da} / \mathrm{dN}$ and $\Delta \mathrm{K}$ was analyzed by the crack propagation behavior, and the fatigue life was evaluated by using the Paris law. As a result, it was clarified that most of the fatigue life was spent on crack initiation and micro crack propagation. [doi:10.2320/matertrans.MC2007108]

(Received October 22, 2007; Accepted January 21, 2008; Published April 25, 2008)

Keywords: non-combustible magnesium alloy, high cycle fatigue, crack initiation, crack propagation behavior, inclusion, fatigue life evaluation

\section{Introduction}

Magnesium alloy is the lightest among practical alloys and is superior in specific strength, rigidity, and recyclability. It is used for the chassis of electronic devices such as mobiles and notebook computers. ${ }^{1)}$ In recent years, in order to reduce $\mathrm{CO}_{2}$ emissions and counter global warming, improvements in fuel economy of vehicles by weight reduction techniques have been studied well and utilization of the magnesium alloy is expected to increase. However, magnesium alloy has a highly combustible nature. Specifically, the molten alloy and chips tend to ignite during the cutting operations. Hence, magnesium alloy is not widely used at present. ${ }^{2)}$

In order to resolve the problem of ignition, non-combustible magnesium alloys were developed by adding calcium (Ca) ${ }^{3-5)}$ By adding $\mathrm{Ca}$, which is more reactive than $\mathrm{Mg}$, the oxidation reaction of $\mathrm{Ca}$ occurs and a coating of calcium oxide is formed on the surface before $\mathrm{Mg}$ ignites. The calcium oxide coating formed on the surface of the magnesium alloy is denser than the normal calcium oxide film and has a high oxygen interruption ability. Therefore, the ignition temperature of the alloy is elevated by $200-300 \mathrm{~K}$.

For machining this non-combustible magnesium alloy, appropriate facilities to interrupt the oxygen, which are necessary in the machining of conventional magnesium alloys, are not necessary. The non-combustible magnesium alloy is suitable for many machining operations for example, cutting, boring, tapping, etc., as normal aluminum alloys and, moreover, chips do not ignite spontaneously. Moreover, the

\footnotetext{
${ }^{* 1}$ Undergraduate Student, University of Electro-Communications, Tokyo (UEC, Tokyo)

${ }^{* 2}$ Graduate Student, University of Electro-Communications, Tokyo (UEC, Tokyo)
}

non-combustible magnesium alloy has the great advantage that it can be welded onsite by TIG and MIG welding, which is not possible with the conventional magnesium alloys.

The non-combustible Ca-added magnesium alloy has been developed based on Al-Zn and Al-Mn system alloys. However, the mechanical properties of the alloy, particularly the fatigue properties, which are critical for use in structural materials, have not yet been thoroughly researched. The series of researches by H. Noguchi et al. show the relation between the fatigue strength and the inclusion size on the AZC312D, AMC602B, and AZC912D extruded alloys. ${ }^{6)}$ However, the initiation of micro cracks and crack propagation behavior have not been reported. In the present study, rotating bending tests were carried out on the AMCa602 extruded alloy to investigate the fatigue property of the material and the micro crack initiation. The crack propagation behavior was investigated in detail using the replication technique.

\section{Material and Experimental Procedure}

\subsection{Material}

The test material used is the extruded non-combustible magnesium alloy AMCa602. The chemical composition is shown in Table 1. AMCa602 is a magnesium alloy based on the Al-Mn system magnesium alloy AM60, which contains approximately $6 \%$ of $\mathrm{Al}$, and to the AM60 alloy, $2 \%$ of Ca is added for combustion resistance. The extrusion conditions of this material are shown in Table 2. In these extrusion

Table 1 Chemical composition of AMCa602 alloy (mass.\%).

\begin{tabular}{cccccccc}
\hline $\mathrm{Al}$ & $\mathrm{Ca}$ & $\mathrm{Mn}$ & $\mathrm{Si}$ & $\mathrm{Fe}$ & $\mathrm{Cu}$ & $\mathrm{Ni}$ & $\mathrm{Mg}$ \\
\hline 5.63 & 2.02 & 0.281 & 0.022 & 0.003 & 0.005 & 0.001 & Bal. \\
\hline
\end{tabular}


Table 2 Extruding conditions of AMCa602 alloy.

\begin{tabular}{cccc}
\hline $\begin{array}{c}\text { Output Temp. } \\
{[\mathrm{K}]}\end{array}$ & $\begin{array}{c}\text { Billet Temp. } \\
{[\mathrm{K}]}\end{array}$ & $\begin{array}{c}\text { Extrusion Rate } \\
{[\mathrm{m} / \mathrm{min}]}\end{array}$ & $\begin{array}{c}\text { Extrusion } \\
\text { Ratio }\end{array}$ \\
\hline 430 & 370 & 2.7 & 96.3 \\
\hline
\end{tabular}

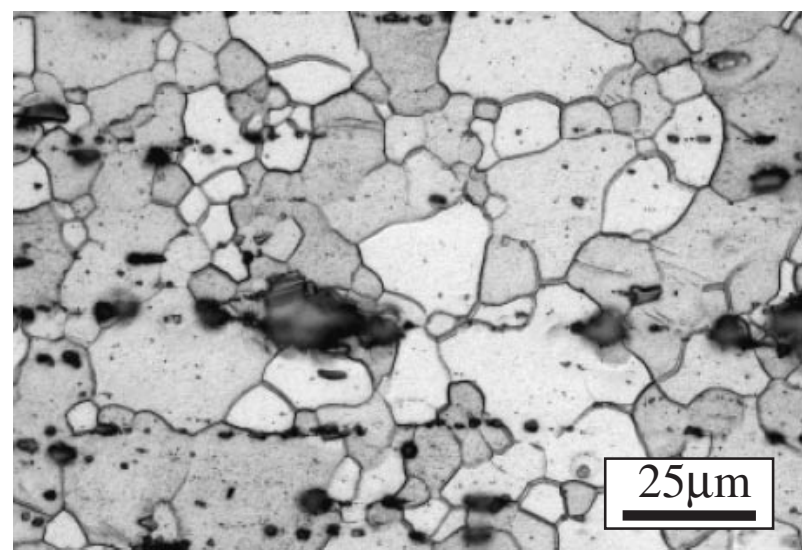

Fig. 1 Microstructures of AMCa602 alloys.

Table 3 Mechanical property of AMCa602 alloy.

\begin{tabular}{ccccc}
\hline $\begin{array}{c}\text { Young's } \\
\text { modulus, } \\
\mathrm{E} / \mathrm{GPa}\end{array}$ & $\begin{array}{c}\text { Tensile } \\
\text { strength, } \\
\sigma_{\mathrm{B}} / \mathrm{MPa}\end{array}$ & $\begin{array}{c}0.2 \% \text { Proof stress, } \\
\sigma_{0.2 \%} / \mathrm{MPa}\end{array}$ & $\begin{array}{c}\text { Elongation } \\
(\%)\end{array}$ & $\begin{array}{c}\text { Vickers } \\
\text { Hardness } \\
\mathrm{Hv}\end{array}$ \\
\hline 40 & 273 & 203 & 9 & 57 \\
\hline
\end{tabular}

conditions, round bars of $\phi 16 \mathrm{~mm}$ were prepared. Figure 1 shows the microstructure of a plane parallel to the extrusion direction. In this material, grains with sizes of approximately $30 \mu \mathrm{m}$ and smaller grains with sizes less than $10 \mu \mathrm{m}$ coexist. The average grain size is approximately $12 \mu \mathrm{m}$, measured according to JIS G0551. There was no difference in grain sizes by the observation direction. It was observed that inclusions exist in a discontinuous manner parallel to the extrusion direction. The mechanical properties of the material determined by a tensile test (a crosshead speed of $0.5 \mathrm{~mm} / \mathrm{min}$ ) and the Vickers hardness test (a load of $1.96 \mathrm{~N}$ and a loading time of $30 \mathrm{~s}$ ) are shown in Table 3.

\subsection{Experimental procedure}

Figure 2 shows the configuration of the fatigue test specimen. The stress concentration factor at the center of the test specimen was 1.05. The test specimen was made from a round bar by machining. Subsequently, a mirror finish was given at the center of the test specimen by wet polishing using emery paper of \#2000 with kerosene, followed by buffing. The fatigue test was conducted on an Ono-type rotating bending fatigue test machine having a rotational speed of $2760 \mathrm{rpm}$ with a stress ratio $\mathrm{R}=-1$. In fatigue tests on magnesium alloys under the highly humid atmospheric conditions, it is well known that corrosion pits, which emerge on the surface of the test specimen, significantly influence the fatigue property. ${ }^{7)}$ In this study, in order to investigate the basic fatigue property of the AMCa602 magnesium alloy in the normal conditions, fatigue testing

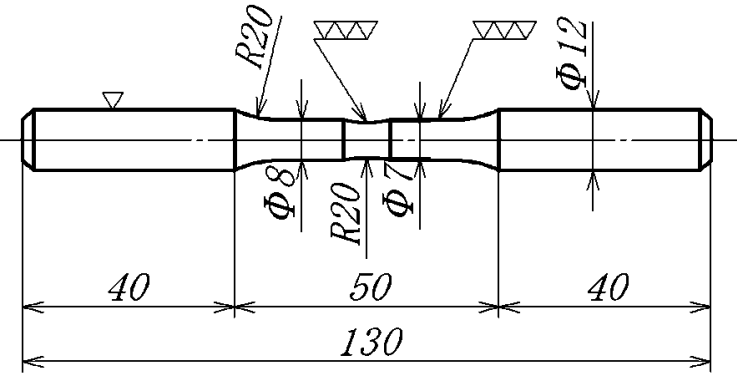

unit : mm

Fig. 2 Shape and dimension of the fatigue test specimen.

was performed at room temperature in the atmosphere. The fatigue test was stopped at $10^{7}$ cycles, and the fatigue strength at $10^{7}$ cycles was defined as the fatigue limit. In order to investigate the crack initiations and crack propagation behavior, an observation of the surface cracks was performed using the replication technique. Moreover, the fracture surface of a test specimen after the fatigue test was observed under a scanning electron microscope (SEM). These experimental methods and conditions are similar to those of the previous study on the extruded AZ31 magnesium alloy by the present authors. ${ }^{8)}$

\section{Experimental Results}

\subsection{Fatigue test results}

Figure 3 shows the S-N diagrams obtained from the fatigue test. The experimental data did not disperse comparatively. In this figure, the experimental results for the AMCa602B material (the tensile strength is $264 \mathrm{MPa} ; 0.2 \%$ proof strength, $188 \mathrm{MPa}$; and Vickers hardness, $69 \mathrm{Hv}$ ), which are reported by Noguchi et al., are plotted. ${ }^{6)}$ The S-N diagrams tended to bend at around $2 \times 10^{5}$ cycles, and the fatigue strength at $10^{7}$ cycles was approximately $100 \mathrm{MPa}$. Compared with the AMCa602B material, AMCa602 has higher tensile strength and $0.2 \%$ proof strength. However, the fatigue strength at $10^{7}$ cycles for $\mathrm{AMCa} 602 \mathrm{~B}$ is $120-130 \mathrm{MPa}$, and that of AMCa602 is even lower.

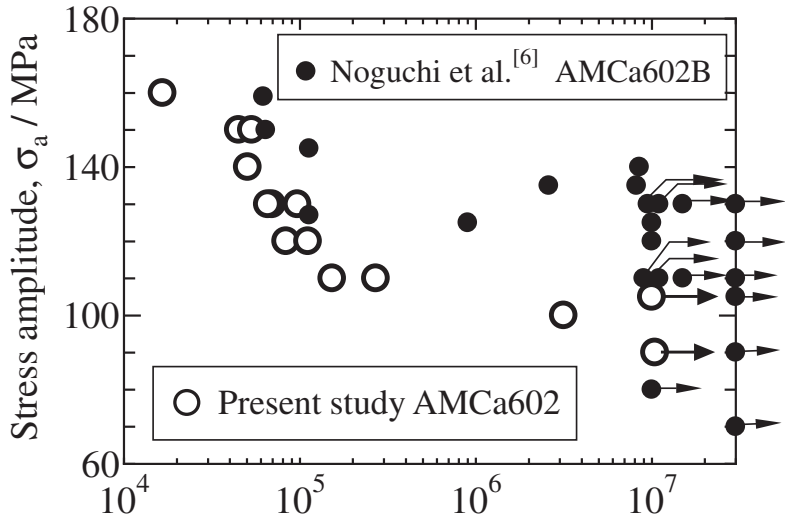

Number of cycles to failure, $\mathrm{N}_{\mathrm{f}} /$ cycles

Fig. 3 S-N diagram compared with other data. 

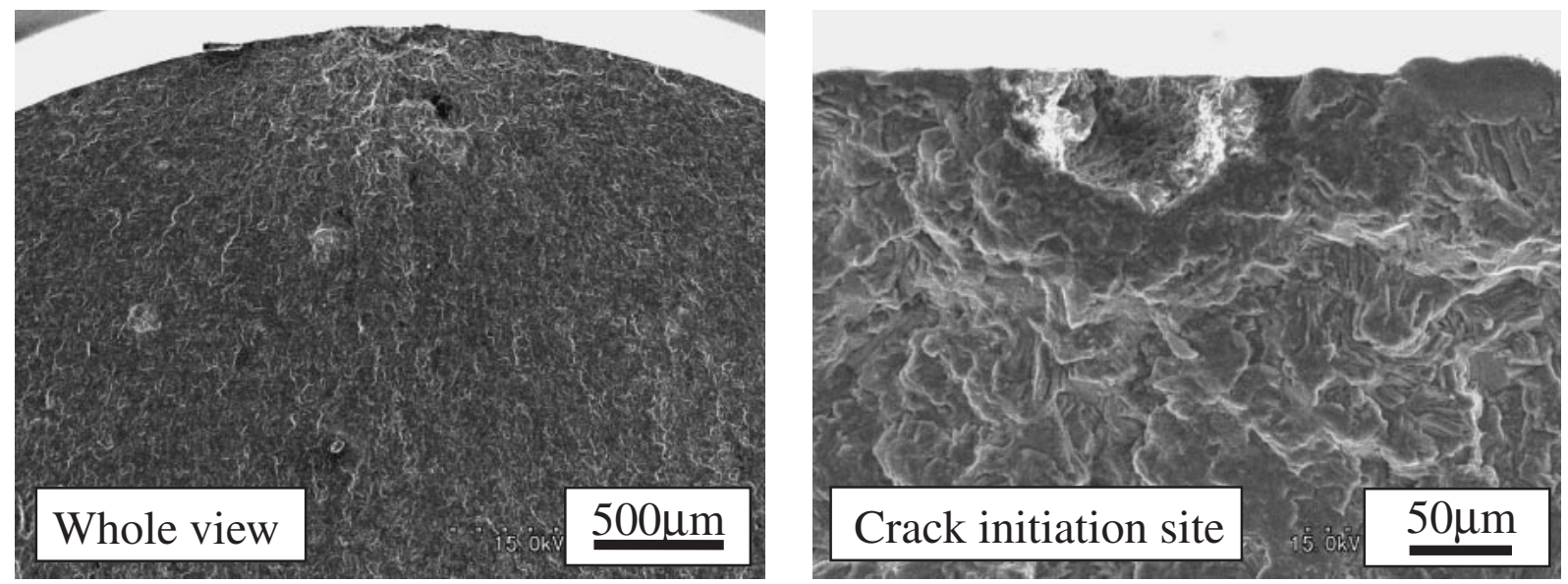

(a) $\sigma_{\mathrm{a}}=130 \mathrm{MPa}, \mathrm{N}_{\mathrm{f}}=6.6 \times 10^{4}$ cycles.
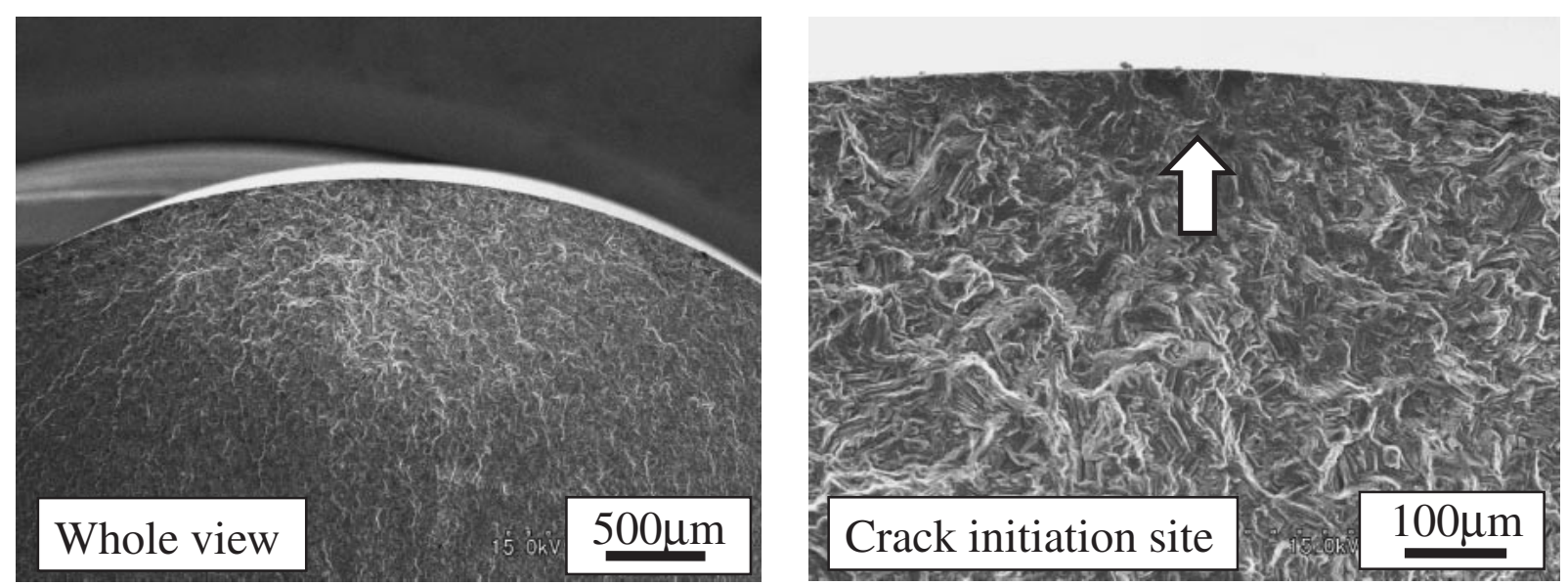

(b) $\sigma_{\mathrm{a}}=110 \mathrm{MPa}, \mathrm{N}_{\mathrm{f}}=1.5 \times 10^{5}$ cycles.

Fig. 4 Examples of fracture surfaces of AMCa602.

\subsection{Fracture surface observation}

The fracture surface was observed by an SEM with the aim of investigating the fracture initiation site and fracture morphology. Figure 4 shows the fatigue fracture surfaces after applied stress amplitude of $130 \mathrm{MPa}$ and $110 \mathrm{MPa}$. It was easy to identify the crack initiation site by the SEM observation. The fracture morphology was such that the crack initiated from the inclusions. This morphology is the same as that observed by Noguchi et al. ${ }^{6)}$ The inclusions at the crack initiation sites exist on the surface except for some rare cases where they exist inside or near the surface. The size of the inclusion at the crack initiation site is around $100 \mu \mathrm{m}$ in diameter. However, in a study by Noguchi et al., the size of the inclusion at the crack initiation site was small (around $50 \mu \mathrm{m})$ in most of the results. It is assumed that the difference in size of the inclusions at the crack initiation site in AMCa602 and AMCa602B is one of the factors leading to the difference in fatigue strengths. The fatigue strength of AMCa602 is dependent on the inclusion size, and it is expected that the fatigue strength could be improved by reducing the size of the inclusions. Besides the inclusions near the fracture initiation site, other bright areas were observed in the SEM images. The sizes of the bright areas

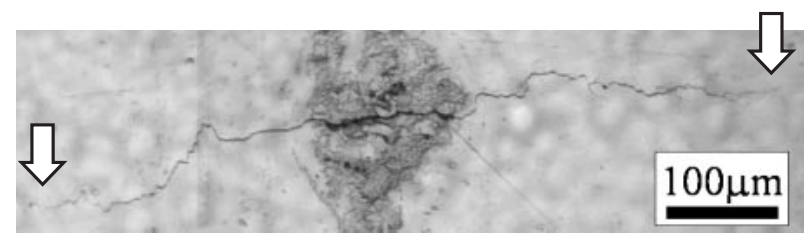

Fig. 5 Example of Surface Crack (replica).

were dependent on the applied stress amplitude. The fracture surfaces in these areas were very rough.

\subsection{Surface crack observation}

Figure 5 shows the appearance of the crack initiation behavior obtained by the replication technique. In this figure, it is clearly seen that the fatigue crack initiated from the inclusion existing on the surface. Occasionally, the crack did not initiate from the inclusion on the surface but from an inclusion inside and near the surface; however, from the SEM observation when the crack initiated from an inclusion inside and near the surface, the initiation site was very near the surface and the crack reached the surface soon after the initiation. The cracks that initiated from inclusions propa- 


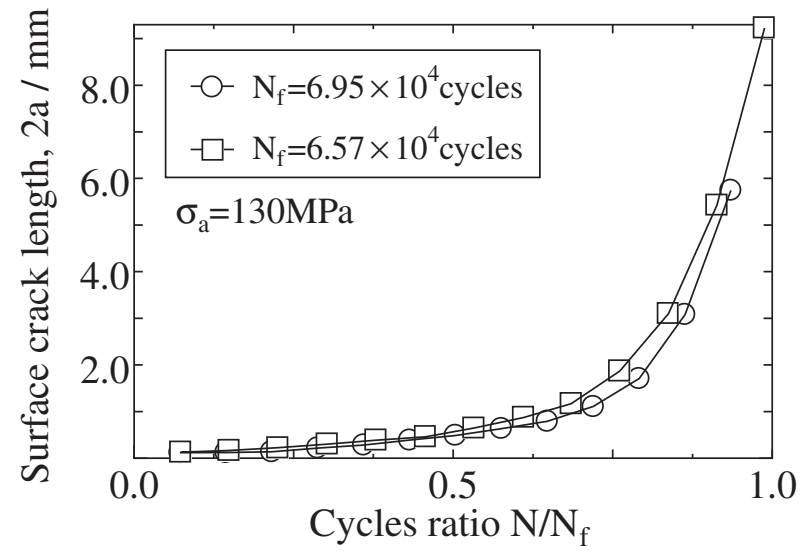

Fig. 6 Relation between crack length 2 a and ratio of number of cycles to failure $\mathrm{N} / \mathrm{N}_{\mathrm{f}}$.

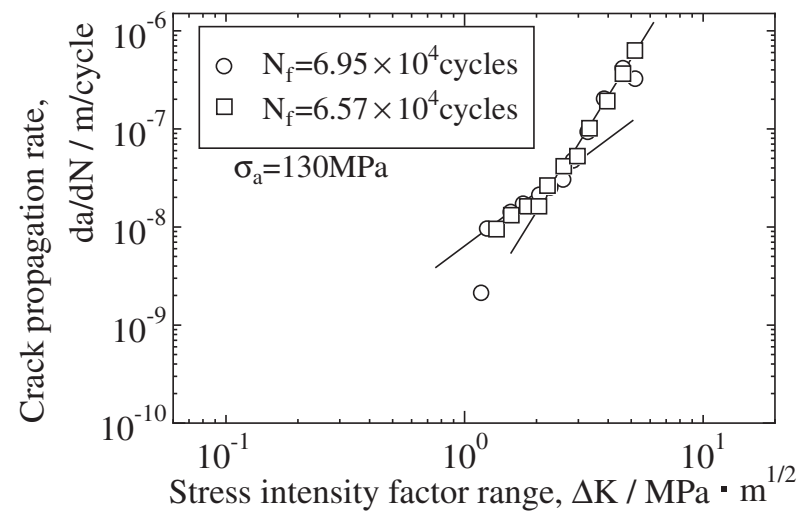

Fig. 7 Relations between crack propagation rate da/dN and stress intensity factor range $\Delta \mathrm{K}$.

gated independently without stopping. Figure 6 shows an example of the crack propagation curve with an applied stress amplitude of $130 \mathrm{MPa}$. It clearly shows that the fatigue crack initiated in an early stage in the fatigue test and that most of the fatigue life was spent on the crack propagation. Figure 7 shows the relation between the crack propagation rate $\mathrm{da} / \mathrm{dN}$ and the stress intensity factor range $\Delta \mathrm{K}$ obtained from Fig. 6 . For the calculation of the stress intensity factor range, the equation given by Y. Murakami et al. was used, ${ }^{9)}$ and for the crack aspect ratio, a value of 1 was used, as used in the previous study on AZ31. ${ }^{8)} \mathrm{The} \mathrm{da} / \mathrm{dN}-\Delta \mathrm{K}$ relation for the AMCa602 alloy has a clear bending point where the stress intensity factor range is $2.7 \mathrm{MPa} \sqrt{\mathrm{m}}$. A bending point in the $\mathrm{da} / \mathrm{dN}-\Delta \mathrm{K}$ relation was also observed in $\mathrm{AZ31} .^{8-10)}$

\section{Discussion}

\subsection{Identification of inclusion at crack initiation site}

The fatigue strength at $10^{7}$ cycles of the AMCa602 material was found to be dependent on the existence of the inclusions on or very near the surface. It was reported by $\mathrm{Z}$. Y. Nan et al. that the inclusion at the crack initiation site of $\mathrm{Mg}-\mathrm{Al}-\mathrm{Zn}$ system magnesium alloy such as AZ31 was the $\mathrm{Mg}-\mathrm{Al}-\mathrm{Zn}$ system $\left(\mathrm{Mg}_{32}(\mathrm{Al}, \mathrm{Zn})_{49}\right)$ or the $\mathrm{Mg}$-Al system $\left(\mathrm{Mg}_{17} \mathrm{Al}_{12}\right){ }^{11)}$ On the other hand, Y. Uematsu et al. reported that the inclusions at the crack initiation sites were of an intermetallic compound of the Al-Mn system, based on a study of the fatigue properties of the AM60 magnesium alloy. ${ }^{12)}$ In the present authors' previous study on the fatigue strength of the extruded AZ31 magnesium alloy, it was observed that the fatigue crack initiated from inclusions with a maximum size of $60 \mu \mathrm{m}$ in diameter. ${ }^{8)}$ Moreover, further investigations made it clear that the crack initiation sites were inclusions of the Al-Mn system. The type of inclusions at the crack initiation site will be dependent on the Mn content and the size of the Mn-containing alloy. ${ }^{13)}$ Because the AMCa602 material does not contain $\mathrm{Zn}$, which is clear from the chemical composition shown in Table 1, it is highly possible that the inclusion is an intermetallic compound of the $\mathrm{Mg}-\mathrm{Al}$ system or the Al-Mn system or even nonmetal inclusions such as the $\mathrm{Ca}$ system $\mathrm{Al}_{2} \mathrm{Ca}$ or $\mathrm{CaO}$. Therefore, we subsequently attempted to identify the inclusion that existed in the material using an electron probe microanalyzer (EPMA).

First, the cross-sectional structure perpendicular to the extrusion direction was analyzed so that the area where the added $\mathrm{Ca}$ existed could be confirmed. Figure 8 shows the EPMA observations; the areas that appear white in the SEM observation are the inclusions observed in the microstructure shown in Fig. 1. These inclusions are comparatively small and not the same inclusions as those at the crack initiation sites. The elements detected from these inclusions were mainly $\mathrm{Al}$ and $\mathrm{Ca}$, and they appear white in the figure. From the analysis of the cross-section, the innumerably scattered inclusions were identified as being $\mathrm{Al}_{2} \mathrm{Ca}$. Subsequently, the comparatively larger inclusions were similarly analyzed by the EPMA; Fig. 9 shows the results. A comparatively large inclusion exists at the center of the SEM image. From the result of the plane analysis, Al, $\mathrm{O}$, and $\mathrm{N}$ were detected in this inclusion; however, neither $\mathrm{Mn}$ nor Ca was detected.

From the above results, it is clear that two types of inclusions exist in the structure. Subsequently, we attempted to identify the inclusion at the crack initiation sites. First, the inclusions existing on the surface of the test specimen were investigated; Fig. 10 shows the results. $\mathrm{Al}$ and $\mathrm{N}$ were detected in an inclusion from which a crack initiated; however, the $\mathrm{Mg}, \mathrm{Ca}$, and $\mathrm{Mn}$ contents were negligible. Figure 11 shows the EPMA results of an inclusion inside and near the surface at a crack initiation site. In this case, the inclusion existed at a depth of approximately $100 \mu \mathrm{m}$ from the surface, and the elements detected in the inclusion were $\mathrm{Al}$ and N, as also shown in Fig. 10. Consequently, in both the types, the surface crack initiation type and the inside and near the surface crack initiation type, the inclusion at the crack initiation site was identified as aluminum nitride (or aluminum oxynitride). It is not certain when the aluminum nitride (or the aluminum oxynitride), which is used as the material for the metal melting crucible, was mixed in (or produced). ${ }^{14)}$ However, the inclusion of the impurities as such is the factor that reduces the actual fatigue strength of the material; therefore, careful attention should be paid while manufacturing the material. The effect of these inclusions on the fatigue strength is discussed in detail in the following section. 


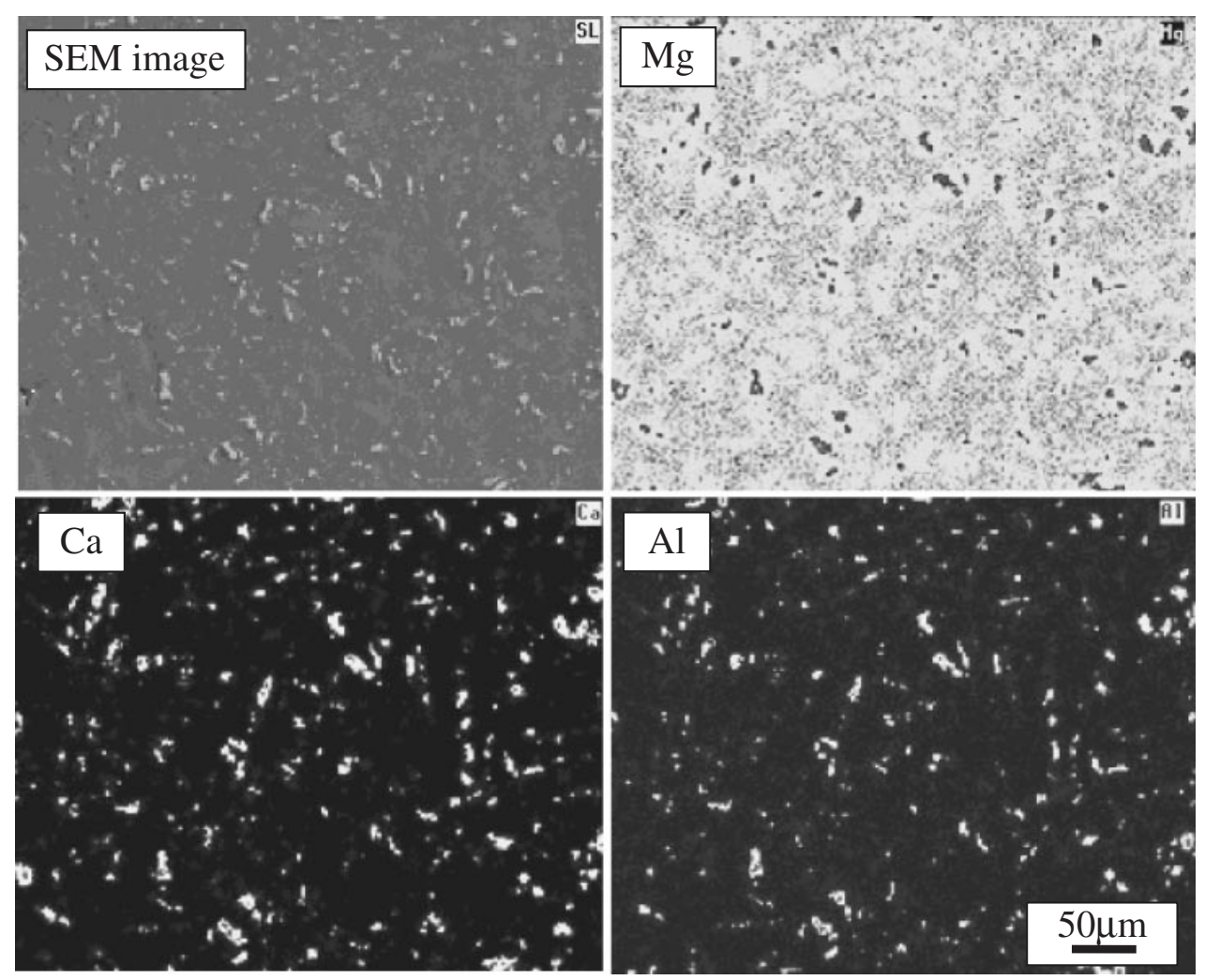

Fig. 8 EPMA result of microstructure of AMCa602.
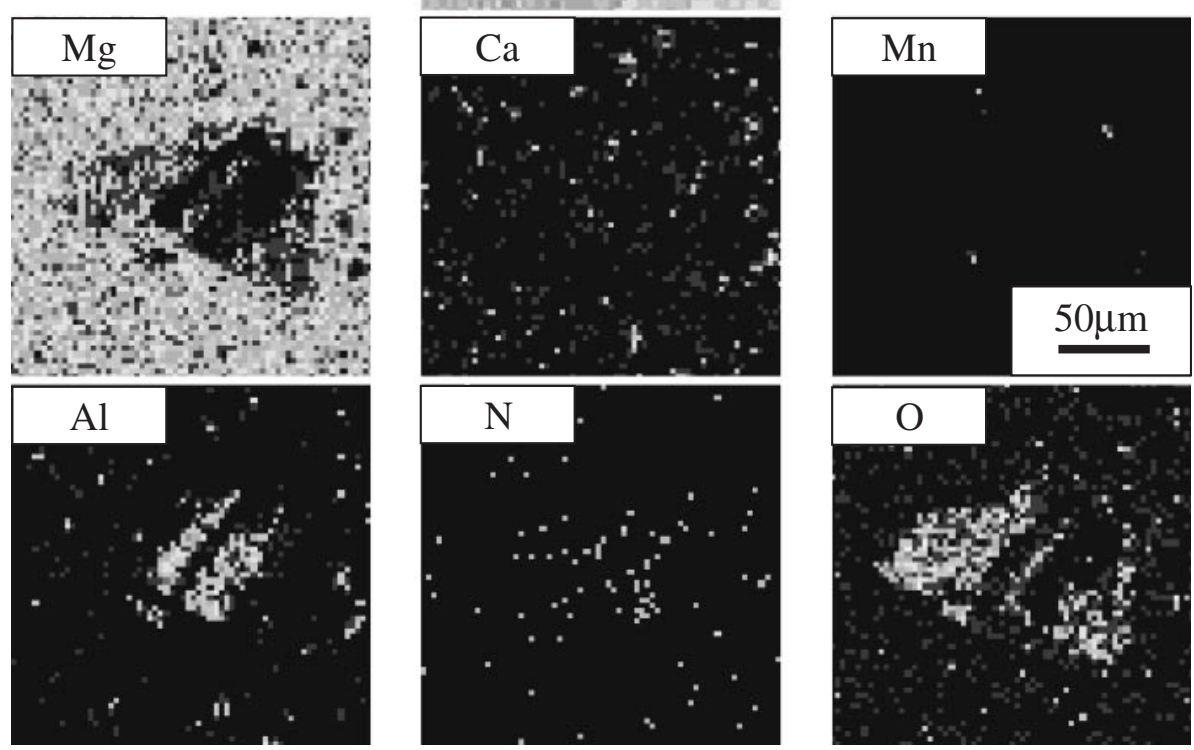

Fig. 9 EPMA result of large inclusion in AMCa602. 


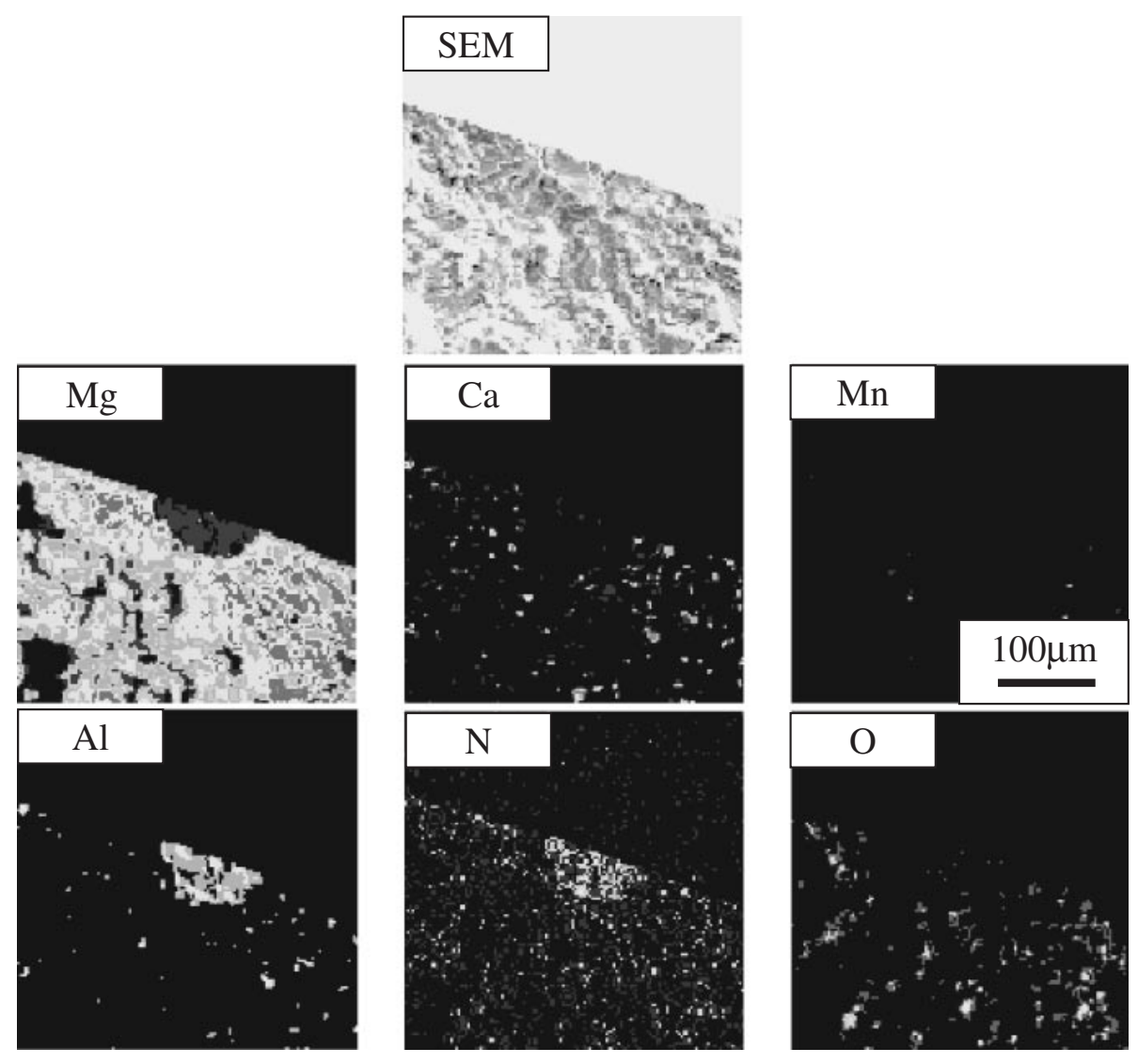

Fig. 10 EPMA result of crack initiation site. $\left(\sigma_{\mathrm{a}}=110 \mathrm{MPa}, \mathrm{N}_{\mathrm{f}}=1.5 \times 10^{5}\right.$ cycles $)$
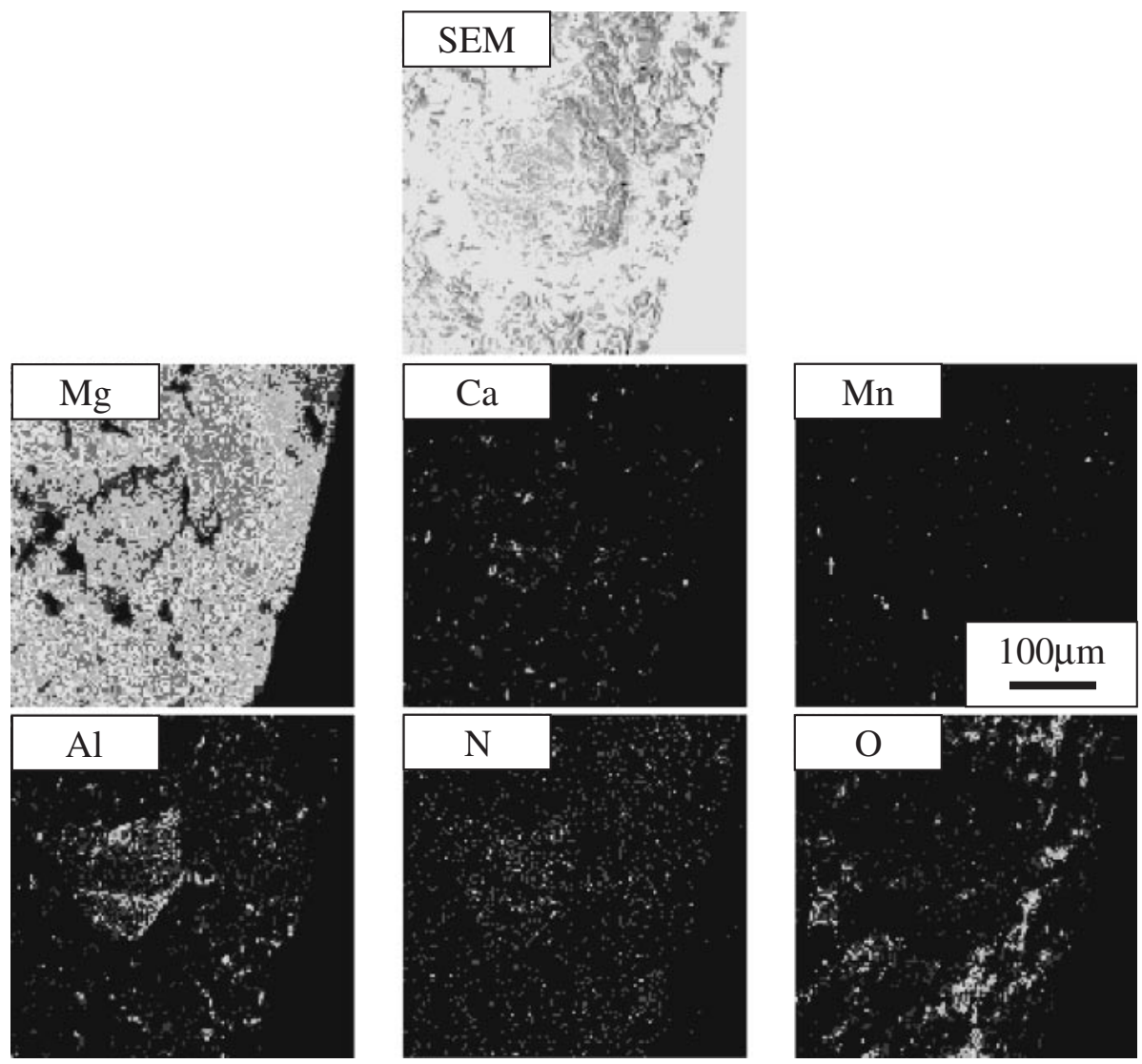

Fig. 11 EPMA result of crack initiation site. $\left(\sigma_{\mathrm{a}}=150 \mathrm{MPa}, \mathrm{N}_{\mathrm{f}}=4.5 \times 10^{4}\right.$ cycles $)$ 


\subsection{Micro crack propagation behavior and inclusion size}

Subsequently, the micro crack propagation behavior was investigated in the range of the fatigue crack length from the initiation up to $500 \mu \mathrm{m}$. As described in Section 4.1, the fatigue crack initiated from comparatively large inclusion of aluminum nitride in most of the test specimens. It is assumed that this crack initiation from aluminum nitride is not the actual crack initiation behavior of AMCa602. Therefore, the micro crack propagation behavior in which the large inclusions were not the crack initiation sites was investigated through multiple observations by the replication technique with an applied stress amplitude of $130 \mathrm{MPa}$. Figure 12 shows the replica photographs of the surface of the test specimen and the crack propagation rate at the corresponding point in the photographs. The replica photographs were taken after etching the surfaces after the investigation of the crack propagation behavior. Figure 12(a) shows a large inclusion that became the crack initiation site, and Fig. 12(b) shows a small inclusion that became the crack initiation site. When the size of the inclusion at the crack initiation site was large, it was observed that the crack propagation rate decreased for a few times, but the crack propagated at a rate of about $10^{-8} \mathrm{~m} /$ cycle immediately after the crack initiation. On the other hand, when the crack initiated from a small inclusion, the crack propagation rate was approximately $10^{-10} \mathrm{~m} /$ cycle shortly after the crack initiation; it gradually increased along with the crack propagation, and when the crack length $2 \mathrm{a}=200 \mu \mathrm{m}$, the crack started to propagate at a constant rate of approximately $10^{-8} \mathrm{~m} /$ cycle. That is to say, even if the crack initiation site was a large inclusion of approximately $100 \mu \mathrm{m}$ in diameter, the crack propagation behavior after the crack length became $2 \mathrm{a}=200 \mu \mathrm{m}$ was that of the original properties of the AMCa602 material. At a crack length $2 \mathrm{a}=200 \mu \mathrm{m}$ under an applied stress amplitude of

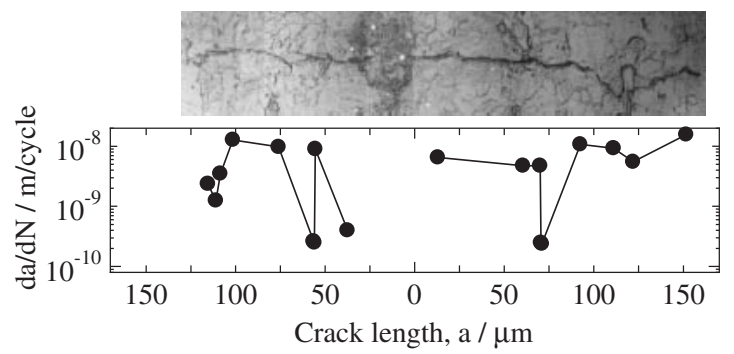

(a) Large inclusion type.

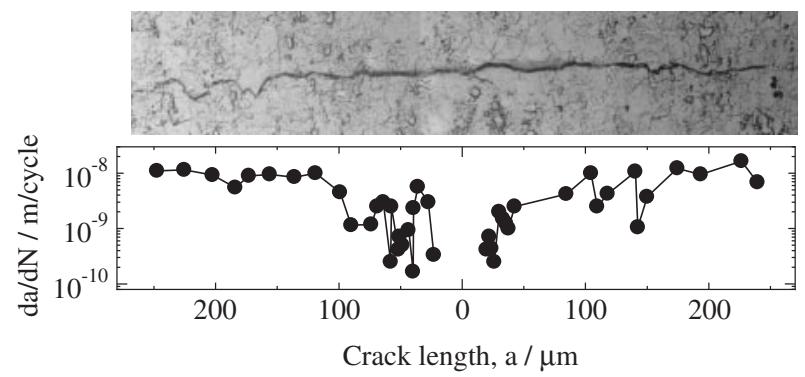

(b)Small inclusion type.

Fig. 12 Microscopic observation and crack propagation rate of small surface fatigue crack.
$130 \mathrm{MPa}$, the stress intensity factor is approximately 1.5 $\mathrm{MPa} \sqrt{\mathrm{m}}$, which precedes the bending point shown in Fig. 7.

\subsection{Crack propagation behavior and stress intensity factor}

There is a clear bending point in Fig. 7, which shows the relation between the crack propagation rate $\mathrm{da} / \mathrm{dN}$ and the stress intensity factor range $\Delta \mathrm{K}$ of AMCa602. In the previous study on AZ31, the appearance of this bending point was explained as being because the crack propagation path changed when the size of the plastic zone at the crack tip, which is dependent on $\Delta \mathrm{K}$, became larger than the grain size ${ }^{8)}$ Before the bending point, the crack propagation path was intergranular, and after that, the path became transgranular. In the former case, the fracture surface exhibited a rough morphology, while in the latter case, the fracture surface exhibited a flat morphology. With the change in the crack propagation path, the crack propagation rate changed such that the bending point appeared in the $\mathrm{da} / \mathrm{dN}-\Delta \mathrm{K}$ curve. To investigate whether this applies to AMCa602 as well, the plastic zone size at the crack tip was calculated and compared with the grain size. The relation between the plastic zone size $r_{p}$ and the stress intensity factor range $\Delta \mathrm{K}$ is expressed by the following equation. ${ }^{15)}$

$$
r_{p}=\frac{1}{2 \pi}\left(\frac{\Delta K}{\sigma_{y}}\right)^{2}
$$

Substituting $\Delta \mathrm{K}=2.7 \mathrm{MPa} \sqrt{\mathrm{m}}$ and $\sigma_{\mathrm{y}}$ (yield stress) $=$ $203 \mathrm{MPa}$, which is the $0.2 \%$ proof strength of AMCa602, the plastic zone size $r_{p}$ was calculated as $28 \mu \mathrm{m}$. The average grain size of the AMCa602 material used in this study was approximately $12 \mu \mathrm{m}$. Grains with sizes ranging from $10 \mu \mathrm{m}$ or less to approximately $30 \mu \mathrm{m}$ coexisted. The plastic zone size of $28 \mu \mathrm{m}$ estimated in the above calculation is approximately equal to the maximum grain size. When the applied stress amplitudes are $110 \mathrm{MPa}$ and $130 \mathrm{MPa}$, the half crack length with which the stress intensity factor range $\Delta \mathrm{K}$ is $2.7 \mathrm{MPa} \sqrt{\mathrm{m}}$ and the bending points are $1020 \mu \mathrm{m}$ and $680 \mu \mathrm{m}$, respectively. Figure 13 shows the SEM observations with which the crack lengths corresponding to the above calculated values are shown. The half crack length corresponding to the bending point on the da/dN $-\Delta \mathrm{K}$ curve is equal to the depth of the transition area where the fracture surface becomes comparatively flat. From the investigation of the relation between the plastic zone size at the crack tip and the grain size and of the fracture morphology, the reason why the bending point appears in the AMCa602 material is because the crack propagation path changes, as in the case of AZ31.

Subsequently, the fatigue life was evaluated using the Paris law with the $\mathrm{da} / \mathrm{dN}-\Delta \mathrm{K}$ relation. For the $\mathrm{da} / \mathrm{dN}-\Delta \mathrm{K}$ relation, Equation (2), which is derived from Fig. 7, was used up to the bending point $\Delta \mathrm{K}=2.7 \mathrm{MPa} \sqrt{\mathrm{m}}$, and after that, Equation (3) was used where the aspect ratio of the crack was 1.0

$$
\begin{aligned}
& d a / d N=5.42 \times 10^{-9} \Delta K^{1.86} \\
& d a / d N=3.97 \times 10^{-10} \Delta K^{4.52}
\end{aligned}
$$




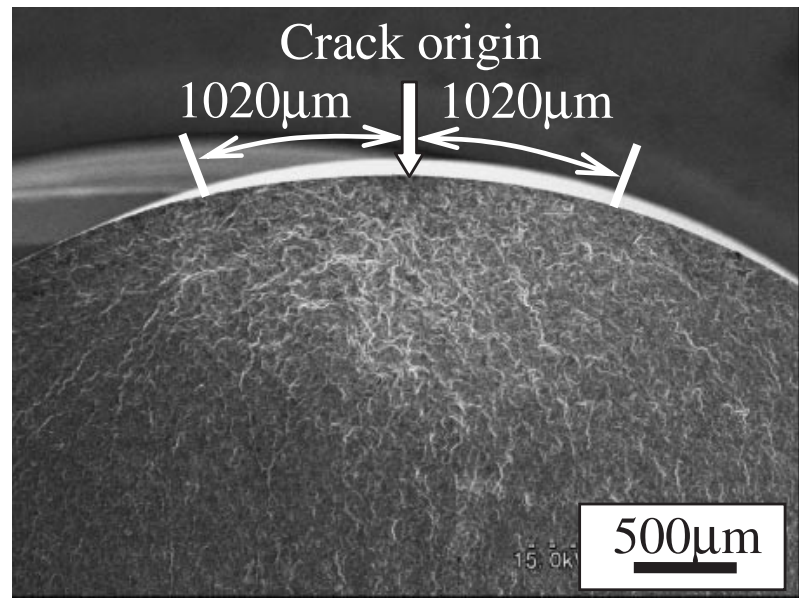

(a) $\sigma_{\mathrm{a}}=110 \mathrm{MPa}, \mathrm{N}_{\mathrm{f}}=1.5 \times 10^{5}$ cycles.

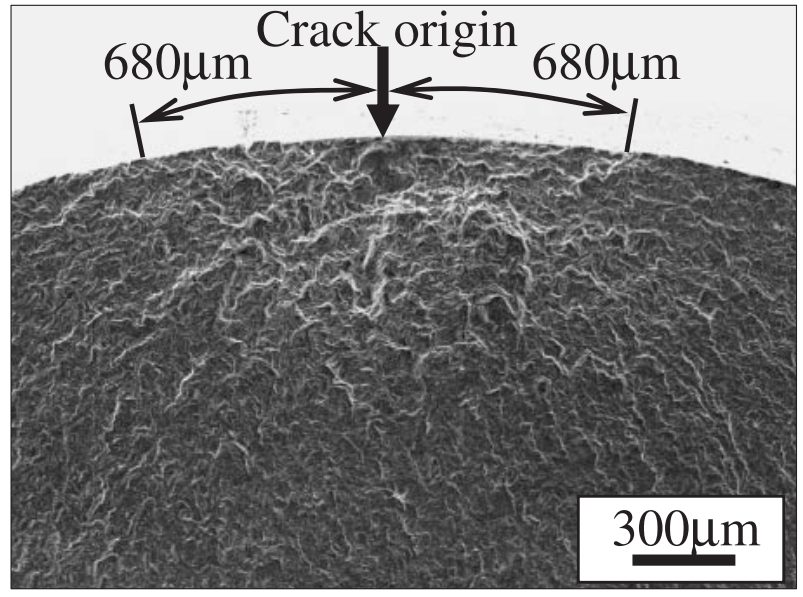

(b) $\sigma_{\mathrm{a}}=130 \mathrm{MPa}, \mathrm{N}_{\mathrm{f}}=1.7 \times 10^{5}$ cycles.

Fig. 13 Bending point of $\mathrm{da} / \mathrm{dN}-\Delta \mathrm{K}$ relation.

The initial and final crack lengths are necessary to evaluate the fatigue life by the Paris law. Here, as the initial crack length, $2 \mathrm{a}_{0}=200 \mu \mathrm{m}$ was used, at which the crack propagation behavior became independent from the inclusion at the crack initiation site, and as the final crack length, $2 \mathrm{a}_{\mathrm{f}}=6300 \mu \mathrm{m}$ was used which is the same value as that of AZ31. Figure 14 shows the $\mathrm{S}-\mathrm{N}$ diagram showing

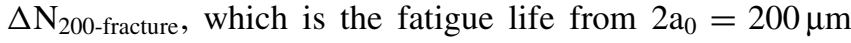

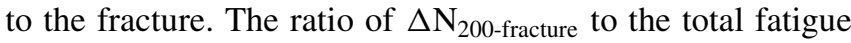
life was approximately $1 / 3$. Hence, the remaining two-thirds of the fatigue life was spent on the crack propagation from the initiation to $2 \mathrm{a}=200 \mu \mathrm{m}$. Here, $\Delta \mathrm{N}_{\text {initiate-200 }}$ is the fatigue life from the crack initiation to $2 \mathrm{a}=200 \mu \mathrm{m}$. The initial crack length corresponds to the size of the inclusion at the crack initiation site: as the inclusion size increases, $\Delta \mathrm{N}_{\text {initiate-200 }}$ decreases. However, when the inclusion is small, not only is the initial crack length small but also the crack propagation rate is also reduced. Thus, the expected increase in $\Delta \mathrm{N}_{\text {initiate-200 }}$ based on the difference in inclusion size is greater than that expected based on the crack initiation size, and moreover, the deceleration of crack propagation rate must also be considered. The variation in $\Delta \mathrm{N}_{\text {initiate-200 }}$ is the cause for the variation in the fatigue life. In this study, since

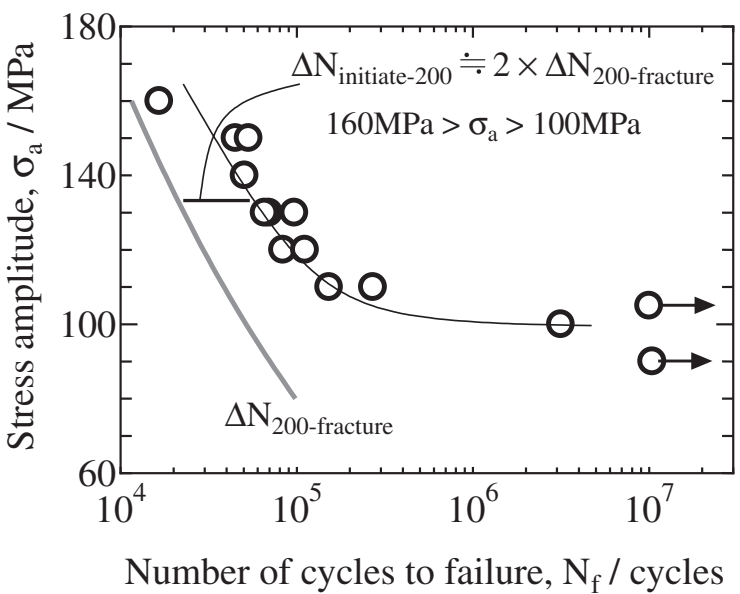

Fig. 14 Fatigue life evaluation.

the sizes of the aluminum nitride inclusions in AMCa602 material were not widely dispersed, the corresponding fatigue test data were also not widely dispersed.

\section{Conclusion}

From the rotating bending fatigue tests on the extruded non-combustible magnesium alloy AMCa602, which is made by the addition of $2 \%$ of calcium to AM60, the following conclusions were derived:

(1) The fatigue crack initiation sites in the AMCa602 magnesium alloy used in this study were inclusions of aluminum nitride (or aluminum oxynitride) which seldom exists in the original material. In the fatigue process of AMCa602, the inclusions affect the crack initiation and micro crack propagation till the crack length reaches $2 \mathrm{a}=200 \mu \mathrm{m}$.

(2) The Ca element in the AMCa602 magnesium alloy was mainly distributed in the matrix in the form of $\mathrm{Al}_{2} \mathrm{Ca}$ of sizes of $10 \mu \mathrm{m}$ or less. Because they were smaller than the other inclusions, $\mathrm{Al}_{2} \mathrm{Ca}$ did not act as a crack initiation site.

(3) In the $\mathrm{da} / \mathrm{dN}-\Delta \mathrm{K}$ relation for the AMCa602 magnesium alloy, a bending point exists over a stress intensity factor range of approximately $3 \mathrm{MPa} \sqrt{\mathrm{m}}$. The reason why the bending point appears is that when the size of the plastic zone at the crack tip exceeds the grain size, the crack preferentially propagates inside the grains; before that, it propagates along the grain boundaries. This behavior is similar to that in AZ31.

(4) Most of the fatigue life of the AMCa602 magnesium alloy was spent on the micro crack propagation; i.e., until the stress intensity factor reached $1-2 \mathrm{MPa} \sqrt{\mathrm{m}}$.

\section{REFERENCES}

1) Y. Murakami and K. Kamei: Non-Ferrous Metallic Materials, (Asakura shoten, Tokyo, 1978).

2) S. Nemoto: Shoho kara manabu maguneshiumu: ichiban karui kinzoku kozozai, (Kogyo Chosakai Publishing Co., Ltd, Tokyo, 2002) pp. 187190.

3) S. Akiyama: J. JFS 66 (1994) 38-42.

4) M. Sakamoto, S. Akiyama, T. Hagio and K. Ogi: J. JFS 69 (1997) 227233. 
5) S. Akiyama, H. Ueno and M. Sakamoto: J. JFS 72 (2000) 521-524.

6) Y. Kitahara, K. Ikeda, H. Shimazaki, H. Noguchi, M. Sakamoto and H. Ueno: Trans. Jpn. Soc. Mech. Eng. A 72 (2006) 661-668.

7) M. Kamakura, K. Tokaji, Y. Ishizumi and N. Hasegawa: J. Soc. Mater. Sci. Jpn. 53 (2004) 1371-1377.

8) Y. Ochi, K. Masaki, T. Hirasawa, X. Wu, T. Matsumura, Y. Takigawa and K. Higashi: Mater. Tran. 47 (2006) 989-994.

9) Y. Murakami: Stress Intensity Factors Handbook, (Pergamon Press, U.K. 1987) p. 657.

10) K. Tokaji, M. Kamakura, Y. Ishizuka and N. Hasegawa: Int. J. Fatigue
26 (2004) 1217-1377.

11) Z. Y. Nan, S. Ishihara, T. Goshima and R. Nakanishi: Scripta Mater. 50 (2004) 429-434.

12) Y. Uematsu, K. Tokaji, M. Kamakura and T. Ohashi: Proc. of the 2005 annual meeting of JSME/MMD 2005 (2005) 213-214.

13) T. Sasaki, Y. Takigawa and K. Higashi: Mater. Sci. Eng. A (2007), doi:10.1016/j.msea.2007.06.038.

14) N. Hotta, I. Kimura, K. Ichiya, N. Saito, S. Yasukawa, K. Tada and T. Kitamura: J. Cera. Soc. Jpn. 96 (1988) 731-735.

15) A. J. McEvily and Z. Yang: Met. Trans. A 21A (1990) 2717-2727. 